\title{
O MUNICÍPIO E OS DESAFIOS DA POLÍTICA URBANA EM AGLOMERADOS URBANOS: A EXPERIÊNCIA DA METRÓPOLE FLUMINENSE
}

\author{
THE CITY AND CHALLENGES OF URBAN POLICY IN URBAN AGLOMERATES: THE EXPERIENCE OF RIO DE JANEIRO
}

\section{RESUMO}

A institucionalização de regiões metropolitanas no Brasil vem se desenvolvendo desde o século XX sob a lógica hora do centralismo autoritário dos governos militares, hora do fortalecimento dos governos locais designado pela Constituição de 1988. O processo é complexo e a formação das principais regiões metropolitanas da região sudeste ainda está longe de se concluir. Mesmo o Estatuto da Metrópole, nascido em 2015, não foi capaz de dirimir todos os conflitos atinentes à construção da política urbana em aglomerados urbanos. No Rio de Janeiro em especial, a construção da região metropolitana envolvendo a antiga capital federal demonstra como o tema ainda desafia governos estaduais e municipais. Neste artigo, foi realizada uma breve retrospectiva histórica da construção da região metropolitana fluminense, além da análise dos impasses jurídicos decorrentes da sua concepção e um debate acerca da trajetória da reformulação por qual passou recentemente a Região Metropolitana do Rio de Janeiro.

Palavras-chave: Região Metropolitana. Política urbana. Município. Estado.

\section{ABSTRACT}

Since the twentieth century, the institutionalization of metropolitan regions in Brazil has been in progress. Sometimes under the concept of an authoritarian centralism of military governments, sometimes under the concept of strengthening of local governments designated by the 1988 Constitution. This is a complex process, and the formation of the main metropolitan regions of the Southeastern Region is still away of its ending. Even the Metropolis Statute, born in 2015, wasn't able to resolve all conflicts related to the construction of urban policy in urban agglomerations. In Rio de Janeiro in particular, the construction of the metropolitan region involving the former federal capital demonstrates how the issue still challenges state and municipal governments. In this article, a brief historical retrospective of the construction of the metropolitan region of Rio de Janeiro was carried out, as well as the analysis of the legal impasses arising from its construction and a debate about the recent trajectory of the reformulation of the Metropolitan Region of Rio de Janeiro.

Keywords: Metropolitan Region. Urban public policies. Municipalities; State.

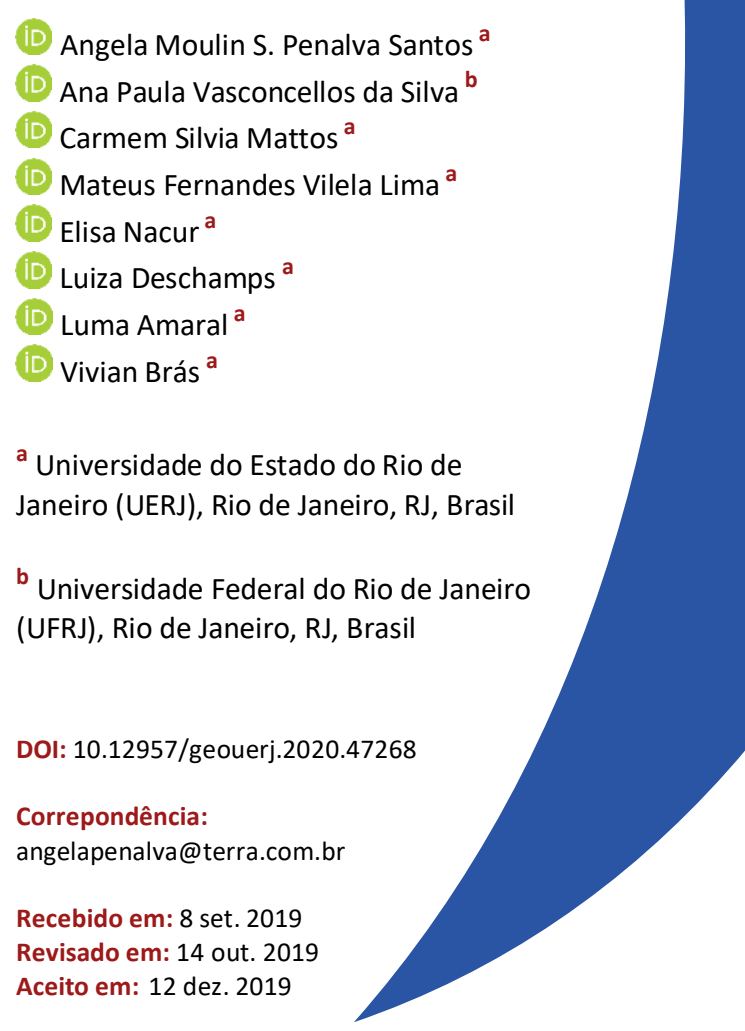




\section{INTRODUÇÃO}

Depois de uma primeira década do século XXI, marcada pelo crescimento econômico e avanço normativo da política urbana, a década seguinte experimentou crises econômicas e políticas que colocaram em xeque sua trajetória. A crise econômica aprofundou o subfinanciamento da política urbana municipal, afetando também o financiamento dos governos estadual e federal, enquanto a crise política diminuiu as condições de governabilidade, necessárias para implementação de dimensões da política urbana dependentes de relações interfederativas estáveis.

É neste contexto que surge a demanda de criação de Agências Metropolitanas no esteio do Estatuto da Metrópole, que têm como objetivo promover uma política urbana integrada entre os municípios que compõem uma Região Metropolitana institucionalizada a fim de garantir gestão plena nos moldes desta norma. Este estudo tem como objetivo analisar o caso da metrópole fluminense, visando refletir sobre os desafios da governança das Regiões Metropolitanas, territórios que não são juridicamente reconhecidos como entes federativos.

Sendo um arranjo territorial que surge como estratégia do governo autoritário para controlar e direcionar as obras de infraestrutura, desenvolve-se de maneira heterogênea no território nacional após o processo de redemocratização, marcado pela Constituição Cidadã de 1988. Apesar do avanço legislativo que se coroa com o Estatuto da Metrópole - Lei no 13.089/15 - evocando o modelo cooperativo entre os entes de um mesmo aglomerado urbano, um aspecto ainda pende de avanço: a autonomia orçamentária e o custeio tanto das estruturas metropolitanas quanto para custeio das medidas necessárias para atingir as Funções Públicas de Interesse Comum as quais este dispositivo se refere ${ }^{1}$.

Para atingir o objetivo ao qual se propõe, parte-se de um panorama das Regiões Metropolitanas organizadas em torno das capitais estaduais do Sudeste, passando por uma apresentação da discussão jurídica que se desenvolveu sobre as Funções Metropolitanas de Interesse Comum (FPICs), com destaque para a discussão suscitada pela região deste estudo, que chegou a ter alguns aspectos discutidos no Supremo Tribunal Federal e que repercutiriam no marco regulatório das regiões metropolitanas, para a partir disso apresentarmos o processo de institucionalização da RMRJ e as conclusões deste trabalho

\section{A Região Metropolitana do Rio de Janeiro em comparação com as Regiões Metropolitanas do Sudeste}

\footnotetext{
${ }^{1}$ Cabe destacar que a proposta de inclusão de um fundo no próprio Estatuto da metrópole foi vetada e que que no ano da edição da lei, 2015 , o país enfrentou uma crise que levou a uma queda de $3,8 \%$ do PIB, seguida de outra queda de $3,6 \%$ no ano seguinte, de 2016.
} 
A Região Metropolitana do Rio de Janeiro (RMRJ) foi criada em 1974, após a fusão dos estados da Guanabara e Rio de Janeiro (Lei Complementar Federal n. 20/1974). Para gerir este território metropolitano, foi criada, em 1975, a Fundação para o Desenvolvimento da Região Metropolitana do Rio de Janeiro, FUNDREM, que durante 15 anos foi responsável pela promoção de convênios de assistência técnica para viabilizar a elaboração dos planos diretores municipais, pela coordenação de programas e projetos de interesse regional e pela viabilização de estudos e pesquisas.

Com a redemocratização e a autonomia municipal conferida pela Constituição de 1988, tal órgão foi gradativamente perdendo poder político e, sem recursos para financiar investimentos metropolitanos, acabou por ser extinta em 1989 pelo Executivo estadual, o que acaba por estabelecer um lapso temporal de quase três décadas na articulação do planejamento integrado no Rio de Janeiro. Experiência que não se desenvolveu de maneira homogênea em relação aos demais estados da região sudeste, como indica o quadro a seguir:

Quadro 1 - Comparação entre Regiões Metrop.: Rio de Janeiro, Vitória, São Paulo e Belo Horizonte Fonte: Elaboração própria com base em dados do sítio eletrônico IBGE Cidades e sítios eletrônicos de órgãos estaduais.

\begin{tabular}{|c|c|c|c|c|}
\hline RM/DADOS & RMRJ & RMGV & RMSP & RMBH \\
\hline POPULAÇÃO ${ }^{2}$ & 13.005 .430 & 1.951 .673 & 21.571.281 & 5.313 .480 \\
\hline $\begin{array}{l}\text { POP DO ESTADO } \\
\% \text { NA REGIÃO } \\
\text { METROPOLITANA }\end{array}$ & $\begin{array}{l}17.159 .960 \\
75,79 \% \text { da } \\
\text { população na RMRJ }\end{array}$ & $\begin{array}{l}\text { 3.972.388 } \\
\text { 48\% da População na RMGV }\end{array}$ & $\begin{array}{l}45.538 .936 \\
47 \% \text { da população na RMSP }\end{array}$ & $\begin{array}{l}21.040 .662 \\
\text { 25\% da População na } \\
\text { RMBH }\end{array}$ \\
\hline № DE MUNICÍPIOS & 22 & 7 & 39 & 34 \\
\hline $\begin{array}{l}>1 \text { MILHÃO } \\
\text { HABITANTES }\end{array}$ & $\begin{array}{l}2 \text { (Rio de Janeiro e } \\
\text { São Gonçalo) }\end{array}$ & Não há & 2 (São Paulo e Guarulhos) & 1 (Belo Horizonte) \\
\hline $\begin{array}{l}500 \text { MIL ATÉ } 1 \\
\text { MILHÃO HABITANTES }\end{array}$ & $\begin{array}{l}4 \text { (Duque de Caxias, } \\
\text { Nova Iguaçu, } \\
\text { Belford Roxo, } \\
\text { Niterói) }\end{array}$ & 1 (Serra) & $\begin{array}{l}3 \text { (São Bernardo do Campo, } \\
\text { Santo André, Osasco) }\end{array}$ & 1 (Contagem) \\
\hline $\begin{array}{l}100 \text { A } 500 \text { MIL } \\
\text { HABITANTES }\end{array}$ & 10 municípios & 4 municípios & 21 municípios & 6 municípios \\
\hline $\begin{array}{l}<100 \mathrm{MIL} \\
\text { HABITANTES }\end{array}$ & 6 & 2 & 13 & 26 \\
\hline $\begin{array}{l}\text { TEM AGÊNCIA } \\
\text { METROPOLITANA? }\end{array}$ & $\begin{array}{l}\text { Teve a FUNDREM } \\
\text { entre } 1975 \text { e } 1989 .\end{array}$ & $\begin{array}{l}\text { Não, sua atuação se dá pelo } \\
\text { Conselho Metropolitano de } \\
\text { Desenvolvimento, através da } \\
\text { Lei Complementar no } 318 \text {, de } \\
18 \text { de janeiro de } 2005\end{array}$ & $\begin{array}{l}\text { Teve a Empresa } \\
\text { Metropolitana de } \\
\text { Planejamento (EMPLASA), } \\
\text { fundada em 1975, até a sua } \\
\text { extinção em } 2019 \text { pela Lei } \\
\text { Estadual no } 17.056 .\end{array}$ & $\begin{array}{l}\text { Teve a Superintendência da } \\
\text { Região Metropolitana de } \\
\text { Belo Horizonte (PLUMBEL), } \\
\text { entre } 1974 \text { e } 1996 . \\
\text { Em } 2009 \text { criou a Agência } \\
\text { RMBH. }\end{array}$ \\
\hline $\begin{array}{l}\text { CRIOU UMA } \\
\text { AGÊNCIA } \\
\text { METROPOLITANA } \\
\text { APÓS O ESTATUTO } \\
\text { DA METRÓPOLE? }\end{array}$ & $\begin{array}{l}\text { Sim, criada pela lei } \\
\text { complementar } \\
\text { estadual 184/2018 } \\
\text { de } 27 \text { dez. } 2018 \text {. }\end{array}$ & $\begin{array}{l}\text { Não, mas instituiu o Plano de } \\
\text { Desenvolvimento Urbano } \\
\text { Integrado - PDUI, através da } \\
\text { Lei Complementar no } 872 \text {, de } \\
07 \text { de dezembro de } 2017 \text {. }\end{array}$ & $\begin{array}{l}\text { Não. Até } 06 \text { jun. 2019, a } \\
\text { função cabia a Emplasa. }\end{array}$ & $\begin{array}{l}\text { Não, mas já havia criado } \\
\text { uma em } 2009 . \\
\text { Porém a agência RMBH não } \\
\text { cumpre os requisitos do } \\
\text { Estatuto, uma vez que não } \\
\text { há representação dos } \\
\text { poderes executivos dos } \\
\text { municípios no órgão }\end{array}$ \\
\hline
\end{tabular}

${ }^{2}$ Números retirados da estimativa de população para 2018, calculada pelo IBGE. 
O quadro anterior situa a RMRJ em relação as demais nucleadas por capitais estaduais da Região Sudeste, onde se situam os quatro estados que produzem 55,2\% do PIB brasileiro (IBGE, 2015). A metrópole fluminense é a segunda maior aglomeração urbana do país, contando com 22 municípios, dois dos quais com população superior a 1 milhão de habitantes e 4 com população na faixa entre 500 mil e 1 milhão, ultrapassando a marca da RMSP com 3 municípios nesta classe de tamanho. Trata-se da região metropolitana mais polarizada espacialmente, o que se associa a sua particularidade de se organizar em torno de uma antiga capital do país, papel que cumpriu por um período de quase 200 anos (1763-1960), e que via de regra resultava em governos distintos entre o seu núcleo, a Cidade do Rio de Janeiro, e a sua área de entorno.

Essa peculiaridade institucional deveria suscitar maior compromisso do governo estadual na articulação do seu território metropolitano no momento da fusão entre os Estados da Guanabara e do Rio de Janeiro, após os 15 anos da experiência como Cidade-Estado, o que não ocorreu. A FUNDREM, que deveria cuidar da articulação socioeconômica do território metropolitano, foi extinta sem que outro órgão dedicado ao planejamento metropolitano tivesse sido criado. É flagrante a diferença do ocorrido nos outros Estados, especialmente em São Paulo, onde a EMPLASA atuou sem interrupção desde sua criação em 1975 até ser extinta em 2019.

Somente em 1997 que o governo estadual fluminense voltaria a legislar sobre a RMRJ por meio da Lei Complementar $n$ ㅇ 87/97, que teve a maioria de seus dispositivos declarados inconstitucionais em 2013, por conceder mais poder ao governo estadual em detrimento dos municípios integrantes. Estabelece-se assim uma verdadeira lacuna institucional em relação ao território metropolitano, que é reforçada pela ausência de regramento claro para financiamento das Funções de Interesse Metropolitano Comum da Lei Complementar no 184/18, deixando a cargo dos seus membros como, e em que proporção, o Fundo de Desenvolvimento da Região Metropolitana será alimentado. Medida que apesar de democrática, teria a opção legislativa pela inserção de valores e fontes específicas na ordem legal uma estratégia para dirimir possíveis embaraços à realização do novo modelo de governança.

Um contraponto pode ser ilustrado na legislação capixaba ${ }^{3}$ que trouxe no seu bojo a determinação de que o Fundo Metropolitano de Desenvolvimento da Grande Vitória - FUMDEVIT, alimente-se de recursos equivalentes a $40 \%$ oriundos dos municípios e $60 \%$ do Estado em relação ao montante equivalente a cada

\footnotetext{
${ }^{3}$ Art. 11. Fica criado o Fundo Metropolitano de Desenvolvimento da Grande Vitória - FUMDEVIT, vinculado à SEP, cuja execução orçamentária-financeira ficará a cargo do IPES, com a finalidade de dar suporte financeiro ao planejamento integrado e às ações conjuntas de interesse comum entre o Estado e os Municípios integrantes da RMGV.

$\S 1$ 응 0 total dos recursos a serem carreados para o FUMDEVIT, provenientes do Estado e dos Municípios previstos no inciso I deste artigo, obedecerá aos seguintes critérios: I - o Estado transferirá para o Fundo 60\% (sessenta por cento) do montante estipulado; II o conjunto dos Municípios integrantes da RMGV carreará para o FUMDEVIT recursos equivalentes a 40\% (quarenta por cento) do montante estipulado, de forma proporcional, no tocante a cada município à respectiva participação na arrecadação do Imposto sobre Operações Relativas à Circulação de Mercadorias e sobre Prestações de Serviços de Transporte Interestadual e Intermunicipal e de Comunicação - ICMS da Região.
} 
ação definida pelo órgão competente; sendo que a parte municipal está vinculada a respectiva participação, de cada município, na arrecadação do Imposto sobre Operações Relativas à Circulação de Mercadorias e sobre Prestações de Serviços de Transporte Interestadual e Intermunicipal e de Comunicação - ICMS da Região. Determinando uma participação significativa do estado no aporte financeiro, indicando que seu papel frente a governança metropolitana não se restringe ao privilégio de mediação e peso nas deliberações, mas sim de ente instituidor da RM, cabendo participação financeira compatível com este papel ${ }^{4}$.

Diferentemente de Vitória, a Região Metropolitana de Belo Horizonte (RMBH) apresenta deficiência quanto às fontes de recursos do Fundo de Desenvolvimento Metropolitano - FDM, que foi criado pela Lei Complementar estadual $n^{\circ} 88 / 2006^{5}$, mas é composto essencialmente de dotações e transferências de recursos do estado e da União ${ }^{6}$, sem, no entanto, estabelecer qualquer regra para o valor, a periodicidade e o volume dos recursos, o que acarreta, na maioria das vezes, a ausência desses repasses.

Por outro lado, em 2009, por meio da Lei Complementar no 107 foi criada a Agência de Desenvolvimento da Região Metropolitana de Belo Horizonte - Agência RMBH -, na forma de autarquia territorial e especial, com caráter técnico e executivo, para fins de planejamento, assessoramento e regulação urbana, viabilização de instrumentos de desenvolvimento integrado da RMBH - e apoio à execução de funções públicas de interesse comum, com autonomia administrativa e financeira, personalidade jurídica de direito público. Entretanto, com relação ao Plano de Desenvolvimento Urbano Integrado da RMBH, aprovado em 2011 por sua Assembleia Metropolitana e Conselho Deliberativo, cabe salientar que ao ser submetido como projeto de lei à Assembleia Legislativa, foi arquivado em razão do final da legislatura? .

No caso da metrópole paulista se instituiu, através do Decreto Estadual no 59.094 de 2013, o Fundo de Desenvolvimento da Região Metropolitana da Grande São Paulo (FDM) - regulamentando o capítulo IV da Lei

\footnotetext{
${ }^{4}$ Nesse molde o Conselho Metropolitano de Desenvolvimento da Grande Vitória (COMDEVIT) aprova projetos específicos obedecendo ao critério de repasse referente a $60 \%$ do valor total feito pelo estado e $40 \%$ pelos municípios, sendo o mecanismo adotado para execução das ações metropolitanas, estas que até o momento estiveram centradas na elaboração de estudos e planos sobre a RM da Grande Vitória, tais como o Plano Diretor de Transporte Urbano, Estudo de Uso e Ocupação do Solo e Circulação Urbana, PDUI entre outros; que se financiaram com FUMDEVIT que foi implementado e, devidamente, alimentado entre 2006/2010. Ao passo que, a RMRJ, ao que parece, ainda não implementou seu Fundo Regional.

${ }^{5}$ Art. 18. O Fundo de Desenvolvimento Metropolitano - FDM -, instituído pelo art. 47 da Constituição do Estado, tem como objetivos o financiamento da implantação de programas e projetos estruturantes e a realização de investimentos relacionados a funções públicas de interesse comum nas Regiões Metropolitanas do Estado, conforme diretrizes estabelecidas pelo Plano Diretor de Desenvolvimento Integrado de cada região metropolitana, observadas as normas e as condições gerais estabelecidas nesta Lei. ${ }^{6}$ Art. 21. Constituem recursos do FDM: I - os recursos do Estado e dos Municípios a ele destinados por disposição legal, na proporção de $50 \%$ (cinquenta por cento) de recursos do Estado e 50\% (cinquenta por cento) de recursos dos Municípios que integram a região metropolitana, proporcionalmente à receita corrente líquida de cada Município; II - as dotações orçamentárias ou as transferências da União destinadas à execução de planos e programas sob a orientação do Plano Diretor de Desenvolvimento Integrado; III - os produtos de operações de crédito, internas ou externas, contraídas pelo Estado ou por Município integrante da região metropolitana, para financiamento de funções públicas de interesse comum; IV - os retornos de financiamentos concedidos com recursos do FDM; V - os resultados das aplicações financeiras das disponibilidades transitórias de caixa; VI - as dotações a fundo perdido consignadas ao FDM por organismos nacionais ou internacionais, inclusive por organizações não governamentais; VII - os auxílios, as subvenções, as dotações e outros recursos.

7 Cf. informação de tramitação disponível em:

https://www.almg.gov.br/atividade_parlamentar/tramitacao_projetos/interna.html?a=2017\&n=74\&t=PLC\&aba=js_tabTramitacao
} 
Complementar no 1.139/2011 - com o objetivo de dar suporte financeiro ao planejamento integrado da Região Metropolitana.

A gestora do FDM é a Desenvolve SP - Agência de Fomento do Estado de São Paulo S.A., parte integrante da administração indireta do Estado de São Paulo e subordinada administrativamente à sua Secretaria da Fazenda e Planejamento. A instituição atua por meio das linhas de financiamento e, também, como administradora de Fundos de Desenvolvimento do Estado de São Paulo. Além disso, oferece opções de garantias por meio dos Fundos Garantidores, apoia o crescimento das empresas paulistas, inclusive startups, via Fundos de Investimento em Participações (FIPs), e abrange todo o território paulista por meio das parcerias com órgãos de classe, entidades representativas do segmento empresarial, fabricantes e revendedores de máquinas e equipamentos, comerciantes e prestadores de serviços.

Evidencia-se então que não se trata de agência voltada exclusivamente para o incentivo e implementação de políticas públicas ou governança cooperativa, pois apresenta um viés amplamente econômico e empresarial na sua atuação. Seu objetivo é a promoção do desenvolvimento econômico no Estado de São Paulo, podendo, para tanto, conceber e implantar ações de fomento sob as diferentes modalidades a que alude a Resolução no 2.828, de 30 de março de 2001, do Banco Central do Brasil, incluída a administração, na forma do seu Estatuto Social, de Fundos Especiais de Financiamento e Investimento do Estado (Fundos de Desenvolvimento). De maneira que a RMSP tal como a RMRJ, carece de fundo destinado à concretização das FPICs.

As duas maiores RMs, em população e produção, não lograram definir como compartilhar entre os entes os gastos nestas FPICs em seus territórios metropolitanos. A despeito de definições legislativas a percepção do que seria interesse comum parece alimentar este entrave a efetividade do Estatuto da Metrópole, e haver um mínimo de consenso somente na pauta do saneamento básico, como sugere a referida $A D I n .1842^{8}$ e o discurso do atual Secretário Estadual das Cidades, em entrevista concedida à equipe deste estudo ${ }^{9}$.

A grande heterogeneidade socioeconômica e capacidade orçamentária entre os municípios situados nas RMs pode ser responsável pela resistência à cooperação. Em uma realidade na qual a capital estadual concentra metade da população e do PIB da região metropolitana, existem outros municípios com grande população, como São Gonçalo, Duque de Caxias e Nova Iguaçu, porém de baixo PIB per capita e forte dependência das receitas municipais de fontes externas. São também caracterizados por apresentar um elevado percentual de população com rendimento inferior a meio salário mínimo, o que se traduz em baixa

\footnotetext{
8 “O ponto central discutido nos autos é a legitimidade das disposições normativas ao instituir a RMRJ e a microrregião dos Lagos (Lei Complementar 87/89) transferindo do âmbito municipal para o âmbito estadual competências administrativas e normativas próprias dos municípios, que dizem respeito aos serviços de saneamento básico (Lei Estadual 2.869/97)”. Disponível em: www.stf.gov.br, consulta em 27 ago.2019

${ }^{9}$ Entrevista realizada em 15 jul. 2019 à Elisa Nacur e Luiza Deschamps, da equipe de pesquisadores.
} 
capacidade contributiva. Niterói e Petrópolis se destacam por ter população de médio porte e melhores indicadores socioeconômicos, sendo dois municípios que não sofrem maiores pressões demográficas. Itaguaí e Maricá contam com menos população, pouco superior a 100 mil habitantes, mas apresentaram bons indicadores de PIB, experimentando maior dinamismo demográfico em função de crescimento econômico relativo à função portuária e de petróleo, respectivamente. Os demais municípios apresentam um perfil de maior vulnerabilidade em todos os indicadores, ainda que alguns tenham população significativa como Belford Roxo e São João de Meriti.

Diante de tamanha desigualdade (que também está presente nas demais RMs), como superar a disputa entre prefeituras das capitais e os governos estaduais (os entes com maior capacidade orçamentária) na alocação de gastos de interesse comum, parte dos quais localizados em municípios menores e economicamente mais vulneráveis?

\section{O debate jurídico sobre competências em relação as Funções Públicas de Interesse Comum (FPICs) entre entes federativos da RMRJ}

A região Metropolitana do Rio de Janeiro, surge em um contexto autoritário tal como a Fundação para o Desenvolvimento da Região Metropolitana do Rio de Janeiro (FUDREM), criada um ano após sua instituição. O órgão tinha como objetivo principal a execução de tarefas relacionadas à elaboração e atualização do Plano de Desenvolvimento Integrado da Região Metropolitana do Rio de Janeiro. Quase 15 (quinze) anos após sua criação, foi promulgada a esperada Constituição Cidadã de 1988 que, a despeito de ter consagrado os Municípios como entes federativos, perdeu a oportunidade de se aprofundar na regulamentação da questão metropolitana, relegando à temática apenas um dispositivo ${ }^{10}$, o qual em nada substancialmente acrescentava em relação à Constituição anterior de $1967^{11}$.

Sendo o principal mote da gestão metropolitana o compartilhamento de poder pelos integrantes, o fortalecimento conferido pela atual Carta Constitucional às comunas, não é acompanhado de um aprofundamento da pauta metropolitana, de maneira que percebe-se, como consequência lógica da maior autonomia conferida aos Municípios, o enfraquecimento do poder político do núcleo metropolitano e, consequentemente, da FUDREM, com sua sequente extinção pelo Poder Executivo estadual em 1989.

\footnotetext{
${ }^{10}$ CRFB/1988 - Art. 25 [...] § 3ㅇ Os Estados poderão, mediante lei complementar, instituir regiões metropolitanas, aglomerações urbanas e microrregiões, constituídas por agrupamentos de municípios limítrofes, para integrar a organização, o planejamento e a execução de funções públicas de interesse comum.

CRFB/1967- Art 157 - A ordem econômica tem por fim realizar a justiça social, com base nos seguintes princípios: [...] § 10 - A União, mediante lei complementar, poderá estabelecer regiões metropolitanas, constituídas por Municípios que, independentemente de sua vinculação administrativa, integrem a mesma comunidade socioeconômica, visando à realização de serviços de interesse comum.

${ }^{11}$ Com efeito, inovou ao prever a possibilidade de os Estados, e não mais a União, instituírem as regiões metropolitanas, mas não se aprofundou acerca do Poder Executivo e administrativo dessas regiões e a titularidade da prestação de serviços de natureza comum.
} 
A abordagem, o planejamento e a gestão em escala metropolitana, então, ficou à margem da discussão político-federativa durante anos, até que ao final do governo Marcello Alencar, em dezembro de 1997, quase 10 (dez) anos após a promulgação da Carta Republicana, foi sancionada a Lei Complementar do Estado do Rio de Janeiro no 87 de 1997 que dispunha sobre a região metropolitana do Rio de Janeiro, sua composição, organização e gestão e a definição das funções públicas e serviços de interesse comum.

Não tardou muito até a lei que estabeleceu uma nova governança na região metropolitana do Estado do Rio de Janeiro fosse vigorosamente impugnada nas instâncias judiciais. Logo em meados de 1998, ou seja, menos de 06 meses após sua entrada em vigor, o Partido Democrático Trabalhista (PDT) levou a questão ao Supremo Tribunal Federal por meio da Ação Direta de Inconstitucionalidade no 1.842, a qual igualmente contestava a Lei ordinária estadual no 2.869 de 1997 que dispõe sobre o regime de prestação do serviço público de transporte ferroviário e metroviário de passageiros no estado do rio de janeiro, e sobre o serviço público de saneamento básico no Estado do Rio de Janeiro.

A seara legislativa da Região Metropolitana do Rio de Janeiro tem na Lei Complementar no 184 de 2018 do Estado do Rio de Janeiro, sua mais recente atualização, ao apagar das luzes do mandato do Executivo estadual (2014/18), substituindo ${ }^{12}$ a fatídica Lei Complementar Estadual no 87 de 1997 e sendo ponto de partida para a adequação desta região ao disposto pelo Estatuto da Metrópole. No entanto, não se revela possível investigar as nuances que permearam seu processo legislativo, sem que se analise, ainda que brevemente, a impugnação da Lei Complementar Estadual no 87 de 1997 que a antecedeu, objeto da mencionada paradigmática Ação Direta de Inconstitucionalidade no 1.842 .

Impugnava-se quase a integralidade ${ }^{13}$ das leis sob a acusação de seus dispositivos "usurparem, em favor do Estado e em detrimento dos municípios que integram a chamada Região Metropolitana do Rio de Janeiro, funções e serviços públicos da estrita competência municipal, como tais assegurados, explicita ou implicitamente, na Constituição da República"14.

Nas razões, alegava-se que os dispositivos impugnados desafiavam, em última instância, a autonomia municipal consagrada no artigo $18^{15}$ da Carta Magna, principalmente por concentrar em um único ente, vale

\footnotetext{
12 A Lei Complementar Estadual no 87/97 não foi completamente revogada pela Lei Complementar Estadual no184/18, uma vez que os artigos que instituíam algumas Microrregiões permanecem em vigor.

${ }^{13}$ Com efeito, a lei conta com 13 artigos, tendo sido contestados os artigos 1으 e 2으, parte final; 3으 e seus incisos; 4ㅇ; ;ㅇ; 6ㅇ; 7우; 8ㅇ; 9ㅇ; 10 e 11. Assim como em relação à Lei ordinária no 2.869 de 1997, a qual teve os artigos 8; 90; 10; 11; 12; 13; 14; 15; 16; 17; 18; 19; 20 e 21.

14 Petição Inicial. ADI no 1.842. Supremo Tribunal Federal. http://redir.stf.jus.br/estfvisualizadorpub/jsp/consultarprocessoeletronico/ConsultarProcessoEletronico.jsf?seqobjetoincidente=171 4588 Acesso em 01 ago. 2019

15 CRFB/1988 - Art. 18. A organização político-administrativa da República Federativa do Brasil compreende a União, os Estados, o Distrito Federal e os Municípios, todos autônomos, nos termos desta Constituição.
} 
dizer, no Estado do Rio de Janeiro, o poder decisório e o poder concedente dos serviços de interesse comum, em prejuízo do autogoverno e autoadministração dos Municípios integrantes da Região Metropolitana.

A discussão, que girava em torno precipuamente da autonomia municipal, alcançada justamente com o advento da Carta Constitucional de 1988, não escondia, por outro lado, aquela que se mostra ser a grande obstinação da pauta metropolitana do Rio de Janeiro até os dias atuais: o serviço público de saneamento básico ${ }^{16}$.

Com efeito, a Lei Complementar no 87/97 definia os serviços de interesse comum, atribuindo, logo em seguida, a organização e a prestação de alguns deles, no qual se incluía o serviço de saneamento básico, ao Estado do Rio de Janeiro. A despeito da evidente importância do tema, a questão que se arrastou por longos anos no Supremo somente ganhou traços de definição e deu o primeiro passo para o desembaraço da gestão metropolitana no ano de 2013, isto é, 15 (quinze) anos depois da edição da lei complementar no 87/97 e 25 (vinte e cinco) anos após a promulgação da Constituição. Apesar do interesse específico principalmente no serviço de saneamento, a judicialização da questão teve o condão de entravar a institucionalidade de toda a pauta metropolitana no Estado do Rio de Janeiro enquanto não sobrevinha o julgamento da $A D I^{17}$.

Dentro do Estado permanecia latente, contudo, em alguns setores da Administração, a preocupação com o tema metropolitano, o que ganhou reforço normativo em 2011 com a edição do Decreto no 42.832 que instituiu o Comitê Executivo de Estratégias Metropolitanas - o qual esboçava a posterior Câmara Metropolitana criada - com o objetivo de propor políticas estratégicas para a Região Metropolitana do Rio de Janeiro, visando promover a gestão dos assuntos de caráter metropolitano, resultado do compromisso

\footnotetext{
16 Nem mesmo a própria petição inicial atravessada no Supremo Tribunal escondia a principal preocupação. Os principais fundamentos se debruçavam em demonstrar os efeitos das legislações em referência sobre a concessão do serviço de saneamento básico. O primeiro tópico da exordial é todo dedicado a demonstrar o caso concreto do Município de Niterói, no Estado do Rio de Janeiro, em relação à concessão do serviço de saneamento básico, mesmo diante da sabida impertinência de se discutir situações concretas no bojo do controle concentrado de constitucionalidade. E mais, afirma-se, veemente, na petição inicial, que teria sido o caso concreto enfrentado pelo mencionado Município a razão da edição da Lei Complementar no 87/97 e da Lei ordinária no 2.869/97.

Veja-se passagem da petição inicial: “Aliás, não remanesce a mais mínima dúvida de que a edição pelo Estado das duas leis guerreadas na presente ação direta de inconstitucionalidade traduz condenável retaliação em virtude da frustração nas investidas intentadas na via administrativa-licitatória, em boa hora coarctadas pelo Poder Judiciário e pela Corte de Contas.". Cf. Petição Inicial. ADI no 1.842. Supremo Tribunal Federal. Disponível em: http://redir.stf.jus.br/estfvisualizadorpub/isp/consultarprocessoeletronico/ConsultarProcessoEletronico.jsf? seqobjetoincidente=171 4588. Acesso em 01 ago. 2019.

Em consequência, o próprio voto dos Ministros e o acórdão foram tomados predominantemente pela discussão à luz daquele que parecia ser o principal alvo de disputas, ou seja, o serviço de saneamento básico.

${ }^{17 “}$ “... sequer as instituições previstas na lei para a gestão metropolitana ganharam forma, como o Conselho Deliberativo e o Fundo Metropolitano. (sobre trabalhar com o tema da Região Metropolitana) Especificamente dentro do Estado, desde 2007. Início do Governo Cabral, que foi a época em que a gente decidiu abordar isso dentro de uma Subsecretaria criada dentro da Secretaria de Obras, com objetivo de desenvolver projeto com visão metropolitana, muito embora não tivesse sustentação jurídica ainda. Sabíamos que tinha a 87/97, mas era uma questão que estava pendente. A nossa luta até sair a decisão do STF era porque sempre esbarrava na questão de ter uma pendência no STF então 'não dá para avançar'. Um gargalo que a gente não conseguia superar para avançar mais.". (COSTA, Paulo). Cf. FIRMINO, Luiz. COSTA, Paulo. Entrevista sobre a Região Metropolitana do Rio de Janeiro. 04 jul. 2019. Entrevista concedida à Ana Paula Vasconcellos e Luma Amaral.
} 
firmado pelo Estado do Rio de Janeiro com o Banco Mundial quando da formulação do Programa de Habitação e Desenvolvimento Urbano Metropolitano Sustentável.

Em 06 de março de 2013, finalmente, o plenário do Supremo Tribunal Federal, após amplo debate, proferiu o acórdão de mérito. Neste momento, já apontava o Supremo Tribunal Federal que a modelagem considerada válida para a gestão dos interesses metropolitanos seria aquela em que o poder concedente e a titularidade do serviço fossem reconhecidos a colegiado formado pelo Estado e Municípios. Pode-se dizer que o mote principal do julgado foi estabelecer que a administração, execução e decisões dos temas afetos à região metropolitana fossem adotadas de forma compartilhada entre os integrantes, assegurando a todos o direito de deliberarem sobre as questões discutidas e sua gestão.

Por outro lado, esclareceu-se que a participação dos entes nesse colegiado não necessitaria ser paritária, desde que adequada a evitar a concentração do poder decisório no âmbito de um único ente. Ademais, ratificou-se, em consonância com a jurisprudência anterior do Tribunal Superior, que o caráter compulsório da participação dos Municípios em regiões metropolitanas, microrregiões e aglomerações urbanas não seria incompatível com o núcleo essencial da autonomia municipal, no que diferiria da gestão associada por meio de convênios ou consórcios públicos, que ocorreria de modo voluntário.

O Supremo Tribunal Federal ainda indicou o que entende ser interesse comum para fins de delimitação da atribuição metropolitana, o qual incluiria as funções públicas e serviços que atendam a mais de um Município, assim como os que, restritos aos territórios de um deles, sejam de algum modo dependentes, concorrentes, confluentes ou integrados de funções públicas, bem como serviços supramunicipais ${ }^{18}$.

\footnotetext{
${ }^{18}$ Ação direta de inconstitucionalidade. Instituição de região metropolitana e competência para saneamento básico. Ação direta de inconstitucionalidade contra Lei Complementar n. 87/1997, Lei n. 2.869/1997 e Decreto n. 24.631/1998, todos do Estado do Rio de Janeiro, que instituem a Região Metropolitana do Rio de Janeiro e a Microrregião dos Lagos e transferem a titularidade do poder concedente para prestação de serviços públicos de interesse metropolitano ao Estado do Rio de Janeiro.-(...) 3. Autonomia municipal e integração metropolitana. A Constituição Federal conferiu ênfase à autonomia municipal ao mencionar os municípios como integrantes do sistema federativo (art. 1ㅇ da CF/1988) e ao fixá-la junto com os estados e o Distrito Federal (art. 18 da CF/1988).(...) A instituição de regiões metropolitanas, aglomerações urbanas ou microrregiões pode vincular a participação de municípios limítrofes, com o objetivo de executar e planejar a função pública do saneamento básico, seja para atender adequadamente às exigências de higiene e saúde pública, seja para dar viabilidade econômica e técnica aos municípios menos favorecidos. Repita-se que este caráter compulsório da integração metropolitana não esvazia a autonomia municipal. 5. Inconstitucionalidade da transferência ao estado-membro do poder concedente de funções e serviços públicos de interesse comum. 0 estabelecimento de região metropolitana não significa simples transferência de competências para o estado. $O$ interesse comum é muito mais que a soma de cada interesse local envolvido, pois a má condução da função de saneamento básico por apenas um município pode colocar em risco todo o esforço do conjunto, além das consequências para a saúde pública de toda a região. $O$ parâmetro para aferição da constitucionalidade reside no respeito à divisão de responsabilidades entre municípios e estado. É necessário evitar que o poder decisório e o poder concedente se concentrem nas mãos de um único ente para preservação do autogoverno e da autoadministração dos municípios. Reconhecimento do poder concedente e da titularidade do serviço ao colegiado formado pelos municípios e pelo estado federado. A participação dos entes nesse colegiado não necessita de ser paritária, desde que apta a prevenir a concentração do poder decisório no âmbito de um único ente. A participação de cada Município e do Estado deve ser estipulada em cada região metropolitana de acordo com suas particularidades, sem que se permita que um ente tenha predomínio absoluto. (...) (Supremo Tribunal Federal, ADI no 1842/RJ, dje 16/09/2013)
} 
A decisão proferida pelo Supremo no bojo da ADI no 1.842/RJ em março de 2013, apesar de ainda não ter transitado em julgado ${ }^{19}$, inspirou e orientou a alteração do Projeto de Lei no 3.460 que tramitava na Câmara dos Deputados desde 2004, o qual, impulsionado pelo julgamento do Supremo, mais à frente, deu origem ao marco regulatório da governança interfederativa através da Lei no 13.089 de 2015, conhecida como Estatuto da Metrópole ${ }^{20}$. Especificamente quanto à rejeição da administração concentrada em apenas um único ente, o Estatuto da Metrópole expressamente consagra a gestão compartilhada da região metropolitana ao impor e regulamentar sua governança interfederativa.

Duas leis estaduais para consolidar a RMRJ o que mudou e como estamos?

O que se verifica, no cotejo entre as referidas leis, especificamente no que toca às funções públicas de interesse comum é, em um primeiro olhar, quase nenhuma mudança no elenco das referidas funções. Com efeito, a nova lei se revela, neste elenco, praticamente uma reprodução da lei anterior, somadas algumas novas funções consentâneas com o avanço do tempo ${ }^{21}$ e algumas preocupações normativas expressas com a deferência à autonomia municipal ${ }^{22}$.

No entanto, o que mudou profundamente e merece ser pontuado foi a forma de regulamentação da gestão e execução das funções públicas arroladas, nitidamente resultados do julgamento da ADI no 1842/RJ e do consequente advento do Estatuto da Metrópole. Aquele, imbuído da impossibilidade de concentração de poder apenas no Estado, profetizou, como já explorado, que para ser legítima, a gestão e execução dos serviços públicos de interesse metropolitano deve se dar, seja qual for, de forma compartilhada. Por sua vez, o Estatuto da Metrópole, positivando diversos pontos do acórdão, consagrou no direito positivo brasileiro a necessidade de compartilhamento de poder entre os entes integrantes da região metropolitana e, consequentemente, da gestão e execução das funções públicas de interesse comum. ${ }^{23}$

Portanto, verifica-se que, a despeito de não inovar substancialmente nas matérias consideradas como de interesse comum para fins metropolitanos, a Lei Complementar no 184/2018 reflete na sua estruturação o marco teórico alcançado pelo Supremo na ADI n 1.842/RJ, que determinou o compartilhamento da gestão metropolitana e, portanto, das funções públicas de interesse comum.

\footnotetext{
19 O Partido Popular Socialista (PPS) opôs embargos de declaração em face do acórdão, os quais ainda não foram julgados.

${ }^{20}$ CORDEIRO, Glauber de Lucena. Regiões Metropolitanas: O papel dos parlamentos metropolitanos na governança interfederativa do Estatuto das Metrópoles (Lei no 13.089/15). 1a ed. Rio de Janeiro. Lumen Juris, 2016. Pág. 115 e ss.

21 Tais como a inserção do enfrentamento dos efeitos adversos da mudança do clima - em claro compasso com a preocupação mundial decorrente do princípio da precaução - e serviços de comunicação digital, nos incisos IV e $\mathrm{V}$ do artigo 3 o, respectivamente.

22 Como a menção na alínea "a "do inciso II do artigo 3a "desde que não colidam com competências do ente municipal".

${ }^{23}$ Além de toda sistemática da lei, destaca-se o inciso IX do artigo 2o que ao definir governança interfederativa das funções públicas de interesse comum estabelece que "compartilhamento de responsabilidades e ações entre entes da Federação em termos de organização, planejamento e execução de funções públicas de interesse comum, mediante a execução de um sistema integrado e articulado de planejamento, de projetos, de estruturação financeira, de implantação, de operação e de gestão.".
} 
Ainda no que toca às funções públicas de interesse comum, pontua-se, apenas, o protagonismo, uma vez mais, do serviço de saneamento básico, agora previsto no artigo 3o, inciso II da novel legislação, que foi objeto de acalorados debates durante o trâmite da lei ${ }^{24}$ e permanece sendo a principal preocupação de diversos atores envolvidos na questão metropolitana.

O curioso é que a definição como função pública de interesse comum de outros pontos, talvez juridicamente mais polêmicos do que a própria questão afeta ao saneamento, segue à margem da discussão, como é o caso do ordenamento do uso do solo, que ao menos na nova legislação esclareceu se tratar do ordenamento do solo "territorial metropolitano". Pois, a lei anterior se limitava a estabelecer, no inciso VII do art. 3으, que era função de interesse comum o uso do solo, matéria que, por excelência, é de competência municipal, à luz dos artigos 30, incisos I e VIII e 182, todos da Constituição Federal, mas que, no entanto, não desembocou em acalorados debates como o serviço de saneamento básico.

Superado este ponto, mesmo após intensos debates na academia, nas instâncias judiciais e no processo legislativo, a Lei Complementar no 184 de 2018 foi contestada pelo Município de Rio de Janeiro em 07 de maio de 2019 por meio da Representação de Inconstitucionalidade ${ }^{25}$ parcial da Lei Complementar movida pelo Chefe do Poder Executivo com pedido de liminar inaudita altera pars.

A demanda, originada do Município com maior peso de voto na sistemática proposta pela Lei Complementar no 184/2018 não deve prosperar. Na verdade, a maioria dos dispositivos questionados são aqueles em que a norma submete certos atos à oitiva prévia da Assembleia Legislativa do Estado do Rio de Janeiro $^{26}$, os quais, apesar de parecerem, de fato, inconstitucionais, não tem o condão, no caso de sua invalidade, de ferir de morte toda a sistemática trazida pela Lei.

Neste sentido, isto é, da declaração de inconstitucionalidade apenas das expressões que submetem certos atos à aprovação da Assembleia Legislativa do Estado do Rio de Janeiro, se manifestou o Ministério Público Estadual do Rio de Janeiro no bojo da representação de inconstitucionalidade, o que, reforça, acreditase, a improvável sucumbência de toda a sistemática metropolitana instaurada.

\footnotetext{
24 "Aí tinham algumas preocupações. Niterói, por exemplo, muito preocupada porque ela já concedeu o saneamento para águas de Niterói, muito preocupada com o que ia acontecer com o saneamento dela, e outros externando outras preocupações...Outros Municípios tinham já planos de concessão, como Itaboraí e São João." (FIRMINO, Luiz)

"Quando a gente fez essas audiências lá na assembleia, o ambiente foi muito dominado pela discussão CEDAE, como sempre acontece. Então, a maior parte do teor, do conteúdo, ficava muito a reboque do tema dominante que era a questão CEDAE. E a CEDAE, além de ser relevante, é muito participante. Os sindicatos, a representação na CEDAE é muito ativa (sic). Então dominava muito esse debate." (COSTA, Paulo). Cf. FIRMINO, Luiz. COSTA, Paulo. Entrevista sobre a Região Metropolitana do Rio de Janeiro. 04 jul. 2019. Entrevista concedida à Ana Paula Vasconcellos e Luma Amaral.

25 Processo no 0025236-85.3019.8.19.0000. Rel. Des Des. Antônio lloizio Barros Bastos. Órgão Especial. Tribunal de Justiça do Estado do Rio de Janeiro.

${ }^{26}$ Lei Complementar no 184/2018. Artigo 11, § 60; artigo 13, inciso I, alíneas "c" e "d", e inciso II, alínea "c"; § 5ㅇ, inciso II, do artigo 14 ; artigo 23.
} 
A Região Metropolitana do Rio de Janeiro: os desafios institucionais da aprovação do PDUI e da governança da metrópole fluminense

Através de entrevistas realizadas com gestores estaduais ${ }^{27}$ e consulta ao site Modelar a Metrópole da Câmara Metropolitana do Rio de Janeiro ${ }^{28}$, busca-se nesta seção estabelecer o percurso da questão metropolitana na RMRJ, através da análise dos antecedentes ao processo de elaboração do PDUI e da publicação da Lei Complementar 184/2018.

Em continuidade às tentativas de retomada da discussão metropolitana, ao menos a nível estadual, tratada em tópico anterior, se cria em 2011 uma Secretaria Estadual de Desenvolvimento Regional, que marca o esforço para retomada de um planejamento para além de um ente federativo, passando para uma lógica de regiões. Ainda nesta época começa a aparecer um ator institucional bastante relevante para a retomada da questão metropolitana no Rio de Janeiro, o Banco Mundial (BIRD).

No biênio 2010-2011, foi construído o Programa Pró-Gestão, que se tratou de um financiamento assinado entre governo do Estado do Rio de Janeiro e Banco Mundial e que teve como um dos eixos a questão metropolitana. Além dos recursos financeiros, que foram fundamentais para a construção do Plano Diretor Urbano Integrado (PDUI), o BIRD aportou também conhecimento técnico e ajudou a colocar o tema na agenda estratégica do governo do estado.

Foi criado um Comitê para Ações Estratégicas para a Região Metropolitana do Rio de Janeiro, que ajudou a ampliar o diálogo informal que já existia entre órgãos estaduais e algumas prefeituras municipais. Ainda, a participação da Universidade do Estado do Rio de Janeiro (UERJ) foi fundamental neste processo, trazendo a visão acadêmica sobre os temas de interesse metropolitano e sediando debates e seminários que trataram destes assuntos. Em 2011 foram realizados os Diálogos Metropolitanos, com a participação de especialistas trazidos pelo Banco Mundial e do ministro Gilmar Mendes, relator da ADI no 1842/RJ no STF. Estes encontros foram fundamentais não apenas para que o ministro expusesse o raciocínio que mais tarde serviria de fundamento para o seu voto no julgamento da ADI, como também ajudou a gerar sinergia entre os diversos atores envolvidos na questão metropolitana.

A despeito do processo eleitoral para os municípios, que ocorreu em 2014 (e que gerou mudanças nos quadros político-institucionais das prefeituras envolvidas), o Banco Mundial continuou a apoiar a estruturação da RMRJ, fornecendo capacitações para atores envolvidos e trazendo especialistas de outros países para discutir o tema. Neste novo contexto, o cenário era favorável: havia recursos financeiros disponíveis, o tema

\footnotetext{
27 Vicente Loureiro (ex-presidente da Câmara Metropolitana), Luís Firmino e Paulo Costa. Além destes, também concedeu entrevista à equipe deste estudo o Secretário Estadual das Cidades, Juarez Fialho.

${ }^{28}$ Fonte: https://www.modelarametropole.com.br/rmri/ . Acesso em 30 jul. 2019.
} 
estava na agenda estratégica do governo estadual e existia o Comitê para Ações Estratégicas para a Região Metropolitana do Rio de Janeiro, que foi o embrião para que posteriormente fosse criada a Câmara Metropolitana de Integração Governamental (que de agora em diante será denominada apenas de Câmara Metropolitana).

Este cenário positivo fez com que a Câmara Metropolitana fosse criada em 2014 com duas missões muito claras: (i) retomada do planejamento integrado (principalmente através da construção de bases cartográficas confiáveis e através da construção do PDUI); (ii) construção da governança (que se daria através da elaboração de um Projeto de Lei que reestruturasse a RMRJ). A Câmara teve como paradigma três grandes eixos: A CF/88 (especialmente o art. 25, §3ㅇ); o acórdão do STF para a ADI no 1842/RJ; e o Estatuto da Metrópole, que seria promulgado alguns meses após a sua criação. A partir da criação da Câmara Metropolitana, um novo caminho se desenhou na reestruturação da RMRJ, que passou pela construção do PLC 10/2015 e do PDUI, e pela formalização do Instituto Rio Metrópole e demais órgãos da governança da Região Metropolitana. É o que se discutirá na próxima seção.

A elaboração da Lei Complementar 184/2018 e do PDUI foi longa e trabalhosa, havendo algumas etapas de idas e vindas no processo. Segundo informações dos gestores estaduais entrevistados para esta pesquisa, o PDUI levou mais de 30 meses para se completar (de 2016 a 2018), ficando um tempo paralisado por conta da crise fiscal que se abateu sobre o governo estadual ${ }^{29}$. Embora o processo de criação do Plano tenha sido longo, esta tramitação ajudou a construir um ambiente positivo que facilitou a aprovação da LC 184 em 2018. Para a construção do Plano, a percepção dos gestores estaduais é de que houve engajamento dos representantes das prefeituras dos municípios envolvidos, o que foi importante para que se chegasse a um documento final, entregue em junho de 2018.

De acordo com informações constantes no página oficial Modelar a Metrópole 30, o PDUI é estruturado em três grandes partes: (i) A metrópole que temos (diagnóstico da formação da RMRJ e sua base ambiental, sua dinâmica econômica e populacional e o panorama da gestão pública e da governança metropolitana); (ii) A metrópole que queremos (uma síntese da visão de futuro para a RMRJ, contendo a proposta de novo desenho da metrópole, a visão de futuro e a pauta dos eixos estratégicos, com os objetivos metropolitanos e os pontos-chave da visão de futuro); e (iii) A metrópole que faremos (que destacou os programas de ações prioritárias, a reconfiguração espacial metropolitana, o macrozoneamento e as Zonas de Interesse Metropolitano). Importante destacar que, para construção do PDUI, foram realizadas dezenas de oficinas e grupos de discussão, com participação de representantes de organizações de classe, empresariais e da

\footnotetext{
29 O Estado do Rio de Janeiro entrou no Regime de Recuperação Fiscal criado pela Lei Complementar Federal n. $159 / 2017$ após decreto estadual de "Calamidade Financeira" (Decreto n. 45.692 de 17/6/2016)

30 Disponível em https://www.modelarametropole.com.br/wp-content/uploads/2018/09/Resumo-executivo-Plano-Metropolitanovers\%C3\%A3o-digital PT-1-compressed.pdf . Acesso em 10 ago. 2019.
} 
sociedade civil, instituições acadêmicas, lideranças e profissionais reconhecidos pela sua atuação na região, além de representantes dos 21 municípios da metrópole 31.

De acordo com o Resumo Executivo do PDUI, os elementos-chave das estratégias de implementação são: (i) os cenários estabelecidos, de curto, médio e longo prazos; (ii) a capacidade de investimento dos municípios da RMRJ e do estado; (iii) e as ações integradas, organizadas nas Propostas de Ações Prioritárias (PAPs). Conforme consta no Resumo Executivo, "os cenários tiveram a missão de valorizar as premissas definidas para o Plano, a Visão de Futuro e os Objetivos Metropolitanos, bem como as principais diretrizes dos Eixos Estruturantes e o processo participativo ocorrido durante sua elaboração ${ }^{22}$." Já as PAPs seriam "ideiasforça que abarcam todo um conjunto de prioridades que contempla e integra propostas advindas dos eixos estruturantes e do processo participativo. Os Programas, organizados territorialmente ou por áreas temáticas são emblemáticos e fundamentais para o desenvolvimento da metrópole, promovendo maior sinergia entre as ações, criando marcas positivas no território, e possibilitando resultados mais expressivos ${ }^{33}$."

Interessante observar que na visão constante no PDUI, caberá à Governança Metropolitana o papel de articular fontes de financiamento para os projetos a serem implementados na RMRJ. Seguindo a mesma ótica, os gestores estaduais entrevistados apontam que a implementação do PDUI dependerá da qualidade da governança que se construirá através dos Conselhos (Deliberativo e Consultivo) e do Órgão Executivo (Instituto Rio Metrópole). Embora a LC 184/2018 estabeleça em seu artigo nono que a governança da RMRJ se dará através dos Conselhos e do Órgão Executivo, estabelecendo, ainda, a composição dos Conselhos e algumas de suas atribuições, não está clara ainda como se dará a atuação destes.

Além do mais, resta pendente o modo de funcionamento do Instituto Rio Metrópole. No artigo 13 da LC 184/2018, consta apenas que será uma entidade integrante, para fins organizacionais, da Administração Pública Estadual indireta, submetida a regime autárquico especial e vinculada, para fins organizacionais, ao Governo do Estado, com a função de executar as decisões tomadas pelo Conselho Deliberativo, bem como de assegurar suporte necessário ao exercício de suas atribuições. Falta ainda o decreto regulamentador que permitirá a existência formal da agência metropolitana, restando pendente ainda o regimento interno e o modo de funcionamento deste Órgão Executivo da governança da RMRJ. Por fim, outro aspecto importante que carece de aperfeiçoamento é o próprio PDUI, que precisará ser ajustado em razão da inclusão do município de Petrópolis pela ALERJ durante o processo legislativo.

\footnotetext{
31 Informações disponíveis em: https://www.modelarametropole.com.br/o-plano/. Acesso em 10 ago.2019.

32 Resumo Executivo do PDUI, p. 136. Disponível em: https://www.modelarametropole.com.br/wpcontent/uploads/2018/09/Resumo-executivo-Plano-Metropolitano-vers\%C3\%A3o-digital PT-1-compressed.pdf . Acesso em 10 ago.2019.

$33 \mathrm{lbid}$.
} 
A despeito de ainda carecerem atos normativos que permitam exercer plenamente a governança metropolitana, especialmente no que tange às regras para financiamento das ações relativas às FIPCs, como já se mencionou anteriormente neste artigo, a LC 184/2018 foi um marco importante na reformulação da RMRJ. Dada a sua importância e complexidade, sua tramitação foi lenta e cheia de percalços. É o que se discutirá a seguir.

\section{Aprovação da LC 184/2018: bastidores do processo legislativo}

A RMRJ foi formalmente instituída através da Lei Complementar 184/2018, de 27/12/2018. O processo legislativo foi longo, durou pouco mais de 3 anos. O início se deu em setembro de 2015, quando o Poder Executivo apresentou o PLC 10/2015, em regime de urgência. Na sua justificativa, através da Mensagem 32/2015, o então governador do estado, Luiz Fernando Pezão, argumentou que:

A Lei Complementar Estadual no 87, de 16 de dezembro de 1997, ora em vigor, dispõe sobre a região metropolitana do Estado do Rio de Janeiro, (...). A presente proposta, no entanto, visa substituí-la. É que muitos dos dispositivos da LC 87/97 foram declarados inconstitucionais pelo STF (ADI $\mathrm{n} 01.842$ ). 0 vício apontado pelo Supremo não se refere à afixação legal de interesse comum compartilhado pelos entes integrantes da região metropolitana, nem à compulsoriedade de integrá-la. Na visão da Corte, tais providências não se mostram incompatíveis com a autonomia municipal, e, portanto, foram mantidas neste projeto. ${ }^{34}$ (grifou-se)

Observa-se, portanto, que o Poder Executivo estadual citou alguns dos pontos discutidos na ADI no 1842, destacando o que já havia sido consagrado pelo Poder Judiciário: a gestão compartilhada da região metropolitana e a possibilidade de o ente estadual regulamentar sua governança interfederativa.

Em resposta a esta mensagem do Poder Executivo, o Legislativo encaminhou o PL para aprovação de 11 Comissões: Constituição e Justiça; Legislação Constitucional Complementar e Códigos; Assuntos Municipais e de Desenvolvimento Regional; Política Urbana Habitação e Assuntos Fundiários; Saneamento Ambiental; Defesa do Meio Ambiente; Transportes; Obras Públicas; Servidores Públicos; Tributação Controle da Arrecadação Estadual e de Fiscalização dos Tributos Estaduais; e, finalmente, Orçamento Finanças Fiscalização Financeira e Controle.

Houve parecer favorável em todas as comissões, a despeito de alguns deputados da oposição apresentarem voto contrário em algumas dessas Comissões ${ }^{35}$. Os pareceres de cada Comissão não estão disponíveis online, apenas a informação da aprovação do texto sem emendas pelas Comissões. Curiosamente,

\footnotetext{
34 Cf. projeto disponível em:

http://alerjln1.alerj.rj.gov.br/scpro1519.nsf/e00a7c3c8652b69a83256cca00646ee5/2ea5aadf9ff8f7b083257eba0077190a?0penDoc ument. Acesso em 10 mai. 2019.

35 Apresentaram votos contrários: Flavio Serafinni, Elioma Coelho, Wanderson Nogueira, todos do PSOL, e Dr. Julianelli, da Rede.

Ambos os partidos eram oposição ao governo estadual da época.
} 
a despeito de ter sido aprovada sem emendas em todas as Comissões, ao ser apresentado em plenário para votação, o texto recebeu 200 emendas dos parlamentares estaduais. Destaque-se que não apenas os deputados da oposição apresentaram propostas de emendas, mas também deputados da base do governo, o que sugere que o tema não teve tratamento programático juntamente ao Poder Legislativo estadual.

A despeito de terem ocorrido muitas emendas durante o processo legislativo, a visão dos gestores estaduais entrevistados para a pesquisa é de que o processo não foi conflituoso. Na visão deles, as modificações realizadas pelo Legislativo foram positivas, e o PLC 10/2015 teve uma tramitação muito demorada em razão de conflitos com a concessão de serviços públicos, principalmente de saneamento básico, uma vez que tal concessão prescinde de consulta à Assembleia Legislativa, e com o PLC esta competência seria retirada do Legislativo e passaria ao Conselho da Região Metropolitana.

Ainda, os gestores estaduais explicam que, antes de o Executivo encaminhar o PLC para a ALERJ, foram realizadas duas grandes reuniões com representantes de todas as 92 prefeituras municipais fluminenses, e nestas reuniões houve aprovação da proposta inicial feita pela Câmara. Contudo, os prefeitos decidiram não se envolver de fato na articulação com o Legislativo, uma vez que a proposta era muito complexa e demandava compartilhamento de poder. Na visão dos gestores estaduais, 1/4 das emendas eram positivas, 1/4 repetiam conteúdo que já existia no texto original, 1/4 criavam novas regiões metropolitanas no território fluminense (ou incluíam mais municípios) e $1 \frac{1}{4}$ não faziam sentido algum - o que, na visão deles, é uma proporção "esperada" para um tema de tamanha complexidade, não se configurando, portanto, um processo legislativo conflituoso.

A visão da sociedade civil é um pouco diferente daquela dos gestores estaduais. Há indícios de que o Poder Executivo não fez uma articulação prévia mais aprofundada com setores da sociedade civil para a aprovação do PLC 10/2015, conforme se pode observar na publicação realizada pela Casa Fluminense, entidade da sociedade civil que acompanha temas atinentes à gestão metropolitana:

\begin{abstract}
O Projeto de Lei Complementar foi enviado à Alerj em setembro de 2015 em regime de urgência e nenhuma audiência pública a respeito foi marcada pelas comissões permanentes da casa. Para o deputado Eliomar Coelho (PSOL) houve falha legislativa e falta de protagonismo do governo em trazer - assunto para debate. "É inadmissível que se queira colocar em prática uma política de desenvolvimento urbano para uma região metropolitana sem ter tido discussão, que deveria ter sido promovida pelo Executivo estadual. Não foi. Portanto, cabe ao Legislativo estadual preencher essa lacuna, e não com uma audiência pública, mas com várias" - colocou o deputado. ${ }^{36}$ (grifou-se)
\end{abstract}

Após a apresentação das emendas pelos parlamentares, o relator, deputado André Lazaroni (MDB), optou por deixar o tema "esfriar" antes de retomar a votação, o que talvez explique a demora na tramitação legislativa. A equipe da Câmara Metropolitana empenhou-se em analisar cada uma das emendas e apresentar uma resposta detalhada aos deputados. O Diretor-executivo da Câmara Metropolitana à época realizou

\footnotetext{
${ }^{36}$ Fonte: https://casafluminense.org.br/projeto-que-cria-agencia-executiva-da-metropole-recebeu-mais-de-200-emendas-na-aleri/ Acesso em: 16 mai.2019
} 
tratativas com os líderes partidários e participou de audiências públicas, apresentando aos parlamentares e membros da sociedade civil os fundamentos da proposta ${ }^{37}$. Os gestores estaduais da Câmara Metropolitana declararam que durante as audiências públicas o ambiente foi muito dominado pela questão da concessão do serviço de saneamento básico ${ }^{38}$, o que acabou prejudicando o conhecimento que os deputados detinham sobre o conteúdo do projeto de lei apresentado e levou a debates mais acalorados do que o necessário. Ainda assim, conseguiu-se construir consenso necessário para derrubar as objeções apresentadas inicialmente pelos parlamentares e avançar com o processo de votação.

Ao apresentar o seu parecer quanto às emendas apresentadas, o relator optou por trazer um projeto substitutivo, acatando algumas emendas, aglutinando outras e rejeitando a maior parte delas. Na nova proposta, a natureza jurídica e as fontes de financiamento do Instituto Rio Metrópole, instituição estadual criada para funcionar como Órgão Executivo dos Conselhos Deliberativo e Consultivo da Região Metropolitana, foram mencionadas (embora, como já se mencionou anteriormente, tanto o detalhamento de funcionamento do Instituto Rio Metrópole como as fontes de financiamento continuam pendentes de regulamentação). Além disso, as definições de quais são as FPICs ficaram mais explícitas no artigo terceiro da lei (são as funções públicas e os serviços que atendam a mais de um município, assim como aqueles que, embora restritos ao território de um deles, sejam, de algum modo, dependentes, concorrentes, confluentes ou integrados entre si), embora, pela natureza complexa e multifacetada destas funções, espera-se que serão objeto ainda de muitos conflitos, como já aconteceu com a interposição de ação judicial por parte município do Rio de Janeiro. Por fim, o novo texto buscou incluir a participação da sociedade civil também no Conselho Deliberativo, permitindo que a sociedade civil tenha representação tanto no Conselho Consultivo como no Deliberativo.

O projeto substitutivo foi apresentado para votação no apagar das luzes do governo Pezão, na última quinzena de dezembro - momento em que muitos deputados estaduais haviam sido presos por acusações relativas à corrupção, além de o próprio governador do estado se encontrar preso à época da votação ${ }^{39}$. Ainda assim, o projeto substitutivo foi aprovado pelo legislativo estadual sem emendas, e assim a RMRJ passou a existir com sua nova configuração através da Lei Complementar 184, publicada no Diário Oficial do Estado do Rio de Janeiro em 27 de dezembro de 2018.

\section{O olhar do novo governo estadual à governança metropolitana}

\footnotetext{
${ }_{37}$ Cf. reportagem disponível em: http://www.ofluminense.com.br/pt-br/pol\%C3\%ADtica/gest\%C3\%A3o-compartilhada-\%C3\%A9tema-de-discuss\%C3\%A3o-entre-deputados. Acesso em 16/05/2019.

38 Ao receber ajuda financeira da União frente à calamidade financeira, o governo estadual se comprometeu a vender sua mais importante empresa, a CEDAE (Companhia Estadual de Águas e Esgotos do Estado do Rio de Janeiro), o que foi objeto de projeto de lei votado e aprovado na Assembleia Legislativa do Estado do Rio, mas até a finalização deste artigo ainda não havia ocorrido. 39 Fonte: https://g1.globo.com/rj/rio-de-janeiro/noticia/2018/11/29/pf-esta-nas-ruas-do-rio-para-cumprir-mandados-na-lavajato.ghtml. Acesso em 22 mai.2019.
} 
Todo o debate realizado até a edição da Lei 184/18 se deu anteriormente ao atual mandato do Governador Witzel (2019/2022). Naquele período, estava em curso um avanço institucional visando à cooperação federativa na gestão de aglomerados urbanos, culminando com o Estatuto da Metrópole, quando se iniciava a administração do Governador Luiz Fernando Pezão (2015/2018). Neste quadriênio, contudo, eclodiu uma grave crise econômica e social, manifestando-se numa crise financeira que levou ao já referido decreto de calamidade financeira, em 2016, às vésperas do início dos Jogos Olímpicos do Rio de Janeiro.

Entre os muitos efeitos desta crise, inclui-se o indiciamento e/ou prisão de deputados e do próprio Governador Pezão. A crise política levou a Assembleia Legislativa a deixar de dar prioridade ao tema da governança territorial de sua metrópole. O PL do PDUI só seria votado e aprovado nos últimos dias do mandato do governador Pezão, àquela altura já substituído pelo vice-Governador Dornelles.

Estando ainda em início de governo, é difícil antecipar como o Governo Witzel tratará da governança da metrópole fluminense. Por isso entrevistar o Secretário de Estado das Cidades, Juarez Fialho, pode dar pistas, ainda que preliminares da ação estadual ${ }^{40}$.

O Secretário informa que faz parte do Conselho Consultivo da Câmara Metropolitana, retomando a denominação original da agência que a Lei Complementar 184/18 nomeara como Instituto Rio Metrópole. O presidente eleito da Câmara foi o representante da Casa Fluminense, e não algum representante do governo estadual. Vale dizer, foi assegurada a participação social prevista no artigo 18.

No entanto, na segunda reunião do Conselho Consultivo, ocorrida em 19 de setembro de 2019, o Governador Witzel decidiu excluir todos os representantes da sociedade civil que tinham sido indicados na Primeira Conferência Metropolitana, realizada em Niterói, em 2018 sob a alegação de que seria necessário refazer a eleição do presidente do Conselho Consultivo porque na ocasião da eleição, não tinham sido nomeados seus 47 membros. O resultado foi o afastamento de quadros técnicos da antiga Câmara Metropolitana e que participaram de todo o processo de elaboração do PDUI e da criação da agência metropolitana.

Antes da entrada em vigor da Lei Complementar 184/2018, a Câmara Metropolitana era uma entidade do Governo do Estado, passando a ser tratada atualmente como um órgão de uma unidade federativa, isto é, da RMRJ, o que suscita desafios sobre a participação financeira de cada prefeitura e o governo estadual na implementação e manutenção da própria Câmara. Esse desafio só poderá ser enfrentado após a definição do Conselho Deliberativo, cujo conceito normativo se encontra no artigo 10 da referida lei. Ainda não foram

40 Entrevista realizada em 15 jul. 2019 à Elisa Nacur e Luiza Deschamps, da equipe de pesquisadores. 
escolhidos os seus representantes e que enquanto essa situação perdurar, o Fundo de Desenvolvimento da Região Metropolitana ficará pendente de implementação.

O objetivo quanto ao PDUI é aproveitar os 140 projetos existentes na Câmara Metropolitana, elaborados antes da aprovação da lei que o instituiu. No entanto, em face do regime de recuperação fiscal a que o Estado está submetido (e da persistência da crise econômico-financeira que afeta as finanças também municipais), existem limites para financiar investimentos públicos. Diante dessa realidade, "os investimentos só serão feitos com Parcerias Público-Privadas ou com alavancagem financeira, ou de médio a longo prazo, quando se equacionar o ajuste fiscal que está sendo feito pelo Governo do Estado."

Seguindo o mesmo discurso do governo anterior, o Secretário trata do saneamento básico como uma das principais pautas da RMRJ. "É uma temática muito clara nas questões dos aglomerados urbanos", disse o Secretário que seguiu tratando da contaminação das bacias hidrográficas e da captação de águas como um problema universal entre os municípios, uma vez que se trata de uma questão transfronteiriça. "A RM não tem captação de água, a água vem dos rios Paraíba do Sul e Guandu”. Em face dessa evidência, "a capital não pode ficar focada em suas questões internas quando se trata de um problema que reverbera em toda a região metropolitana".

Apesar disso, o entrevistado destacou um projeto em andamento, em parceria com o Governo Estadual, visando a criar uma Operação Urbana Consorciada na região de Santo Cristo, do Centro da Cidade e do Maracanã, na capital estadual. Seria um projeto metropolitano porque faria a reurbanização de toda a linha férrea do metrô desde a Central do Brasil até o município de Belford Roxo, concomitantemente a um grande projeto habitacional próximo às estações. De acordo com Fialho, "é um grande ganho de mobilidade, por conta das habitações próximas às estações(...) A ideia do policentrismo, de se criar, estimular, novos centros urbanos descentralizados, estimulando o desenvolvimento de mais empregabilidade e desenvolvendo a região". Acredita que se trate do "maior projeto urbanístico desde as reformas Pereira Passos". Depois do ocorrido na Operação Consorciada do Porto Maravilha, e em face do contexto de crise continuada, não cabe esperar tamanha repercussão de projeto ainda sem garantia de participação governamental nem ânimo empresarial. Pelo menos por enquanto, persiste a crise que já é a mais longeva experimentada no país, e mais intensamente no Estado do Rio de Janeiro.

Cabe, entretanto, festejar o entendimento de que o "problema do saneamento básico é muito resultante do espraiamento da região urbana, que também gera outros problemas. Por exemplo, também gera problemas de captação de água." Verifica-se, assim, que o padrão periférico da urbanização vem entrando na agenda das políticas públicas urbanas como um problema, e não mais como uma solução (diante da incapacidade de avançar nas políticas de moradia social). Mas, ainda neste caso, a solução aventada é a articulação entre o estado e o mercado em parcerias público-privadas. Juarez Fialho destacou a possibilidade 
de que se aprove uma lei de saneamento básico em que as concessões de serviços não sejam feitas somente com empresas públicas - caso da CEDAE. O referido projeto de lei (PL 3.261/19), de autoria do Senador Tasso Jereissati (PSDB/CE), está atualmente em tramitação no Congresso Nacional e autoriza a União a participar de um fundo para financiar serviços técnicos especializados para o setor.

O que está por vir? O discurso do Secretário vai numa linha que já vem sendo seguida sem muito êxito, caso o poder público não tenha recursos para se comprometer com os projetos. Numa parceria, os empresários podem adiantar recursos para investimento, mas os contratos devem ser cumpridos, sob pena de desfazimento das parcerias. Esse temor é maior ainda quando os investimentos se realizem em áreas periféricas, onde habita uma população de baixa renda e limitada capacidade contributiva. Em tal situação, é ainda mais imperativa a atuação firme do governo para garantir não apenas a realização das obras e/ou serviços, mas também de viabilizar a redistribuição espacial dos ganhos e ônus dos dispêndios públicos realizados.

\section{CONCLUSÕES}

A Constituição elevou o Município à condição de ente federativo, superando a sua submissão à tutela dos governos estaduais. Esse fortalecimento institucional dos municípios suscitou, porém, uma fragmentação do território num contexto de ampliação dos aglomerados urbanos, alguns dos quais formam importantes metrópoles, a exemplo da Região Metropolitana do Rio de Janeiro.

O Estatuto da Metrópole foi um importante avanço normativo na promoção da gestão de territórios que não são considerados entes federativos. Ao estabelecer condições para gestão plena de regiões metropolitanas, como ter uma agência metropolitana e um plano de desenvolvimento urbano integrado, a Lei 13.089/15 induz a cooperação interfederativa e desafia municípios e governo estadual a negociar as condições dessa cooperação.

Nesse cenário, havia a expectativa de que a metrópole fluminense voltasse a ter uma autoridade metropolitana que gerisse as funções públicas de interesse comum. Desde a extinção da FUNDREM, em 1989, passaram-se três décadas sem um governo, ficando a cooperação interfederativa reduzida a pactos voluntários, que não prosperaram porque a capital não participou e o Estado não logrou negociar uma nova autoridade metropolitana que não ferisse a autonomia municipal.

A Lei Complementar 184/18 veio, enfim, introduzir as condições de gestão plena da Região Metropolitana do Rio de Janeiro: foi aprovado um PDUI e criada uma agência metropolitana. A entrada em vigor da lei, no entanto, ocorreu nos últimos dias de mandato do governo estadual que se empenhou na sua 
aprovação. O novo governo iniciado em 2019 ainda é muito recente para que se possa avaliar seu compromisso com a gestão compartilhada das FPICs.

A festejada eleição de um membro da sociedade civil (Casa Fluminense) para presidir o Conselho Consultivo foi frustrada pela decisão do Governador Witzel de anular a eleição, faltando também definir a constituição do Conselho Deliberativo do órgão e formalizar as atribuições da Câmara Metropolitana. Deve ainda ser destacada a resistência do governo da capital em aceitar a gestão compartilhada do serviço de saneamento básico, uma das mais importes FPICs. A disputa entre governo estadual e capital precisa ser superada para que seja possível avançar na articulação do território da metrópole, ampliando a cooperação na execução de investimentos de interesse comum, o que parece já ser mais frequente nas regiões metropolitanas da região Sudeste.

\section{REFERÊNCIAS}

CORDEIRO, Glauber de Lucena. Regiões Metropolitanas: O papel dos parlamentos metropolitanos na governança interfederativa do Estatuto das Metrópoles (Lei no 13.089/15). 1a ed. Rio de Janeiro. Lumen Juris, 2016

SUPREMO TRIBUNAL FEDERAL, Ação Direta de Inconstitucionalidade no 1842/RJ, Rel. Min. Luiz Fux. Disponível em: http://portal.stf.jus.br/processos/detalhe.asp?incidente=1714588. Acesso em agosto de 2019

RIO DE JANEIRO. Tribunal de Justiça. Processo no 0025236-85.3019.8.19.0000. Rel. Des Des. Antônio lloizio Barros Bastos. Órgão Especial.

Lei 13.089 de12 de janeiro de 2015. Disponível em: http://www.planalto.gov.br/ccivil_03/_ato2015-2018/2015/lei//13089.htm, acesso em agosto de 2019

FIALHO, Juarez. Entrevista sobre a Região Metropolitana do Rio de Janeiro realizada em 15 jul. 2019 concedida às pesquisadoras Elisa Nacur e Luiza Deschamp.

FIRMINO, Luiz. COSTA, Paulo. LOUREIRO, Vicente. Entrevista sobre a Região Metropolitana do Rio de Janeiro realizada em 04 jul. 2019 concedida às pesquisadoras Ana Paula Vasconcellos e Luma Amaral.

FIRMINO, Luiz. COSTA, Paulo. LOUREIRO, Vicente. Resumo Executivo do PDUI. Disponível em: https://www.modelarametropole.com.br/wp-content/uploads/2018/09/Resumo-executivo-Plano-Metropolitano-vers\%C3\%A3odigital_PT-1-compressed.pdf. Acesso em 10 ago.2019. 